\title{
Assessment the Relation Between Neutrophil to Lymphocyte Ratio (Nlr) And Gastric Cancer and Colorectal Cancer Patients at The Diagnosis Time and The Relation Between This Proportion and The Incidence of Metastasis in Them
}

\author{
Farahnaz Ghahremanfard ${ }^{1}$, Ahmad Narimani ${ }^{1 *}$, Mohammad Nassaji ${ }^{1}$ and Raheb Ghorbani ${ }^{2}$ \\ ${ }^{1}$ Internal Medicine Department, Semnan University of Medical Sciences, Semnan, Iran \\ ${ }^{2}$ Social Determinants of Health Research Center, Faculty of Medicine, Semnan University of Medical Sciences, Semnan, Iran
}

Submission: September 10, 2018; Published: October 12, 2018

"Correspondence Address: Ahmad Narimani, Internal Medicine Department, Semnan University of Medical Sciences, Semnan, Iran, Email: doctornarimani@gmail.com

Abstract

Introduction: Gastric and colorectal cancers are two common cancers in Iran. Assessment of Neutrophil to Lymphocyte ratio and CBC Diff are so easy tests and if we tried to find a significant difference between these two cancers and normal population. In some cases, we find a metastasis but we can't find the origin. If we find any significant difference between the NLR of these three groups (Gastric, Colorectal, Normal population), we would use this statement in such cases which we couldn't find the origin of an unknown metastasis.

Methods and Materials: In this Historical Cohort study, patients who diagnosed since 21 March 2013 to 21 September 2016, include in the study. Before starting any treatment, we test a CBC Diff. These patients assess about metastasis in each of them frequent visits.

Results: Mean \pm SD age for gastric cancer patients was $61.5 \pm 12.9$, for colorectal cancers was $60.8 \pm 13.1$, and for normal population was $63.0 \pm 10.2$. $38.3 \%$ of gastric cancer patients, $45.2 \%$ of colorectal cancer patients and $47.3 \%$ of normal population were female. Neutrophil to Lymphocyte ratio in gastric and colorectal cancer patients was significantly higher than normal population. Neutrophil to Lymphocyte ratio has not any effect on the mortality rate. Neutrophil to Lymphocyte ratio in metastatic and non-metastatic gastric colorectal patients didn't differ. There was such a result in gastric cancer patients.

Discussion: This study showed that Neutrophil to Lymphocyte ratio has not any impression on mortality rate. On the other hand, there wasn't any difference between metastatic and non metastatic patients. More studies should be done to get more actual results about relationship between neutrophil to Lymphocyte ratio and mortality of these two common cancers.

Keywords: Gastric cancers; Colorectal cancers; Metastasis, Neutrophil to Lymphocyte ratio (NLR)

\section{Introduction}

Nowadays it's obvios that inflammation has an important role in cancers [1]. Inflammatory cytokines and messenger molecules can play the role of vasogenic and these processes prone a person for maligancies [2]. Inflammatory processes have an important role in developing a cancer and this way could be related to systemic inflammation [3-5]. There are some evidences which show that systemic inflammation indicates prognosis in cancerous patients. Inflammation is measured by biochemical and biological parameters, such as increased CRP, reduced albumin, or increased WBC, Neutrophilm and platelet [6].

Many of these parameters are modified to prognostic proportions or criteria, such as Neutrophil to Lymphocyte Ratio
(NLR) [7] or Glascow Prognosis Score [8] which is a combination of CRP and Albumin.

Neutrophil to Lymphocyte Ratio is an indicator of systemic inflammation and it is indicated that it could be related to bad prognosis in soke types of cancers [9-11]. NLR in recent years became an important proportion and often is used in papers to determine the prognosis of different types of cancers. Measuring of this proportion is not expensive and we can get it just with a check on CBC diff. The question is that is there any difference between NLR of different cancers? If there is, we could use it to diagnose the cancers earlier that histological studies. Another question is that is there any difference between NLR of metastatic 


\section{Cancer Therapy \& Oncology International Journal}

cancers and non-metastatic cancers? In this paper we focused on gastric cancers vs colorectal cancers.

\section{Methods and Materials}

This historical cohort study includes patients who were diagnose for gastric or colorectal cancers from 21 March 2011 to 21 September 2016, in Kowsar Hospital (Iran, Semnan). In these patients, we had a CBC diff plan from when the treatments were not started yet. Our sampling method was convenience sampling. These patients on their follow up process were scanned to diagnose any metastasis and when metastasis was diagnosed, we wrote it in their medical documents. In our checklist we wrote the date of first visit and mentioned that if any metastasis was seen till that time or not. For control group, we used person who had not any serious medical disease and did not use any important medication.

\section{Results}

This research includes 81 gastric cancers, 126 colorectal cancers, and 148 control cases. Mean \pm SD of age on the time of diagnosis, for gastric cancer patients was $61.5 \pm 12.9$, for colorectal cancer patients was $60.8 \pm 13.1$, and for control group was $63.0 \pm$ 10.2 which difference was not significant. $38.3 \%$ of gastric cancer patients, $45.2 \%$ of colorectal cancer patients and $47.3 \%$ of control cases, were female. Gender distribution in three groups has not any significant difference $(\mathrm{P}=0.413)$. In $21 \%$ of gastric cancer patients and $24.6 \%$ of colorectal cancer patients, metastasis was detected which this difference was not significant $(\mathrm{P}=0.547)$.

Distribution of Neutrophil in three groups has significant difference $(\mathrm{P}=0.010)$, which the level of neutrophil in gastric cancer patients $(\mathrm{P}=0.04)$ and colorectal cancers $(\mathrm{P}=0.047)$ was more than control group. But the level of neutrophil in gastric and colorectal cancer patients has not any significant difference $(\mathrm{P}=0.213)$. The level of three grouped have significant difference $(\mathrm{P}=0.001)$, which the level of lymphocyte in gastric cancer patients $(\mathrm{P}<0.001)$ and colorectal cases $(\mathrm{P}=0.020)$ was significantly less than control group, but we did not detect any significant difference between lymphocyte level of gastric and colorectal groups $(\mathrm{P}=0.088)$.

The Neutrophil to lymphocyte ratio in gastric $(\mathrm{P}<0.001)$ and colorectal $(\mathrm{P}=0.038)$ was significantly more than control group. But neutrophil to lymphocyte ratio in gastric and colorectal cancers had not any significant difference $(\mathrm{P}=0.087)$. Results showed that there was not any significant difference between these three groups $(\mathrm{P}=0.091)$. Level of haemoglobin in three groups has significant difference $(\mathrm{P}<0.001)$ which in gastric cancer patients $(\mathrm{P}<0.001)$ and colorectal cancers $(\mathrm{P}<0.001)$ was significantly less than control group but the level of haemoglobin in gastric and colorectal cancer patients, has not any significant difference $(\mathrm{P}=0.789)$. Level of platelet in three groups has significant difference $(\mathrm{P}=0.013)$, which in gasric cancer patients $(\mathrm{P}=0.045)$ and colorectal $(\mathrm{P}=0.06)$, significantly was more than control group. But the level of platelet in gastric and colorectal groups has not any significant difference $(\mathrm{P}=0.555)$. Results showed that gastric/ colorectal cancer patients with and without metastasis, have no difference for assessed parameters $(\mathrm{P}>0.05)$.

\section{Discussion}

In our study NLR in gastric cancer patients and also in colorectal cancer patients was significantly more than control group. But NLR in gastric and colorectal group has no significant difference. Satmi et al. [12] after a research, said that NLR in developed disease, is more than control group. In research of Peng HX [13] on 559 colorectal cancer patients, and the same number of control group, NLR in colorectal cancer patients was significantly more than control group. Lian et al. [14] in a research on 162 gastric cancer patients said that NLR and PLR in these patients is significantly more than control group.

\section{References}

1. Lee BS, Lee SH, Son JH, Jang DK, Chung KH, et al. (2016) Neutrophillymphocyte ratio predicts survival in patients with advanced cholangiocarcinoma on chemotherapy. Cancer Immunol Immunother 65(2): $1-10$

2. Coussens LM, Z Werb (2002) Inflammation and cancer. Nature 420(6917): 860-867.

3. Grivennikov SI, Greten FR, Karin M (2010) Immunity, inflammation, and cancer. Cell 140(6): 883-899.

4. Aggarwal BB, RV Vijayalekshmi, B Sung (2009) Targeting inflammatory pathways for prevention and therapy of cancer: short-term friend, long-term foe. Clin Cancer Res 15(2): 425-430.

5. Mantovani, Allavena P, Sica A, Balkwill F (2008) Cancer-related inflammation. Nature 454(7203): 436-444.

6. Roxburgh CS, DC McMillan (2010) Role of systemic inflammatory response in predicting survival in patients with primary operable cancer. Future Oncol 6(1): 149-163.

7. Guthrie GJ, Charles KA, Roxburgh CS, Horgan PG, McMillan DC, et al. (2013) The systemic inflammation-based neutrophil-lymphocyte ratio: experience in patients with cancer. Crit Rev Oncol Hematol 88(1): 218-30.

8. McMillan DC (2013) The systemic inflammation-based Glasgow Prognostic Score: a decade of experience in patients with cancer. Cancer Treat Rev 39(5): 534-540.

9. Chua W, Charles KA, Baracos VE, Clarke SJ (2011) Neutrophil/ lymphocyte ratio predicts chemotherapy outcomes in patients with advanced colorectal cancer. British journal of cancer 104(8): 12881295.

10. Sharaiha RZ, Halazun KJ, Mirza F, Port JL, Lee PC, et al. (2011) Elevated preoperative neutrophil: lymphocyte ratio as a predictor of postoperative disease recurrence in esophageal cancer. Annals of surgical oncology 18(12): 3362-3369.

11. Stotz M, Gerger A, Eisner F, Szkandera J, Loibner H, et al., Increased neutrophil-lymphocyte ratio is a poor prognostic factor in patients with primary operable and inoperable pancreatic cancer. Br J Cancer 109(2): 416-421.

12. Jung MR, Park YK, Jeong O, Seon JW, Ryu SY, et al. (2011) Elevated preoperative neutrophil to lymphocyte ratio predicts poor survival following resection in late stage gastric cancer. J Surg Oncol 104(5): 504-510.

13. Twine RW, C Morris (1986) Early detection of carcinomas of the right colon: role of hemoglobin and mean corpuscular volume. J Natl Med Assoc 78(3): 187-192.

14. Lino-Silva LS, Salcedo-Hernández RA, Ruiz-García EB, García-Pérez L, Herrera-Gómez Á, et al. (2016) Pre-operative Neutrophils/Lymphocyte Ratio in Rectal Cancer Patients with Preoperative Chemoradiotherapy. Med Arch 70(4): 256-260. 


\section{Cancer Therapy \& Oncology International Journal}

This work is licensed under Creative Commons Attribution 4.0 License

DOI: $10.19080 /$ CTOIJ.2018.12.555841
Your next submission with Juniper Publishers will reach you the below assets

- Quality Editorial service

- Swift Peer Review

- Reprints availability

- E-prints Service

- Manuscript Podcast for convenient understanding

- Global attainment for your research

- Manuscript accessibility in different formats ( Pdf, E-pub, Full Text, Audio)

- Unceasing customer service

Track the below URL for one-step submission https://juniperpublishers.com/online-submission.php 